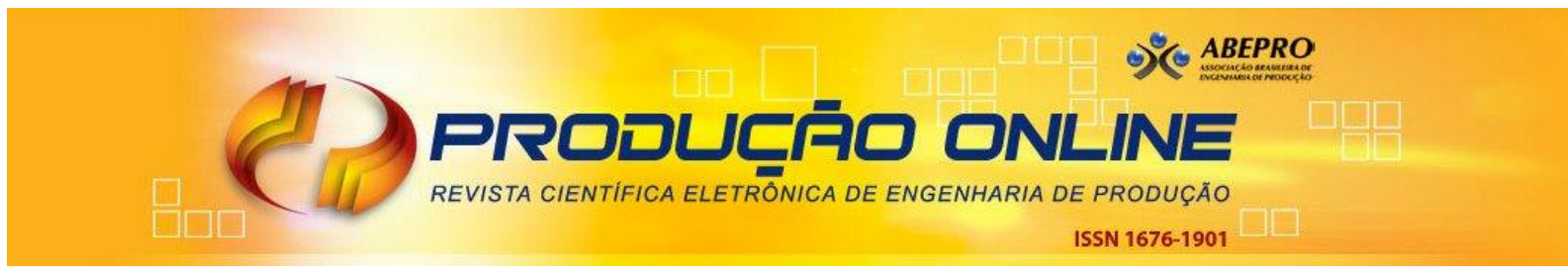

\title{
BIG DATA NO SUPORTE À ESTRATÉGIA DE PRODUÇÃO: ILUSTRAÇÃO DE APLICAÇÃO EM SERVIÇO PÚBLICO
}

\section{BIG DATA IN SUPPORTING PRODUCTION STRATEGY: PUBLIC SERVICE APPLICATION}

\author{
Fernando Celso Campos* E-mail: fernando.campos@unimep.br \\ Alceu Gomes Alves Filho* E-mail: alceu@ufscar.br \\ ${ }^{* *}$ Faculdade de Engenharia, Arquitetura e Urbanismo (FEAU UNIMEP-FEAU/PPGEP), São Paulo, SP \\ **Universidade Federal de São Carlos (UFSCar), São Carlos, SP
}

Resumo: A partir de toda tecnologia relacionada com internet foram surgindo dados disponibilizados nos mais diversos formatos e lugares de armazenamento - o Big Data. Ele suporta as visões gerenciais e estratégicas de um modo novo e dinâmico, eficaz e relevante, combinando fatores e ferramentas. A estratégia de produção é um padrão global de decisões que recebe diretrizes de uma estratégia de negócios, e é altamente dependente de dados e informações. Ela ampliou-se para um padrão geral de decisões determinando competências a longo prazo e contribuições para a estratégia global (requisitos de mercado e recursos de operações). O objetivo desse artigo é apresentar um framework que dê suporte à estratégia de produção utilizando aspectos de Big Data. O método de pesquisa foi realizado em três etapas: i) pesquisa bibliográfica; ii) elaboração de um framework teórico-conceitual; e iii) ilustração de aplicação do framework proposto. A contribuição principal foi a sistematização de uma proposta utilizando-se referencial teórico consolidado de estratégia de produção e referencial mais recente acerca de Big Data. A aplicação em um serviço público gerou uma expectativa de continuidade e de busca por meios tecnológicos para se verificar em quanto tempo se solucionariam os problemas e qual a economia advinda dessa implantação.

Palavras-chave: Estratégia de produção. Big data. Framework. Serviço público. Caso ilustrativo.

\begin{abstract}
From all internet-related technology, data has been made available in the most diverse formats and storage places - Big Data. It supports managerial and strategic visions in a new, dynamic, effective and relevant way, combining factors and tools. Production strategy is a global pattern of decisions that gets guidelines from a business strategy, and is highly dependent on data and information. It has expanded to a general pattern of decisions determining long-term competencies and contributions to the overall strategy (market requirements and operations capabilities). The objective of this article is to present a framework that supports the production strategy using aspects of Big Data. The research method was carried out in three stages: i) bibliographic research; ii) elaboration of a theoretical-conceptual framework; and iii) illustration of the application of the proposed framework. The main contribution was the systematization of a proposal using a consolidated theoretical reference of production strategy and the latest reference on Big Data. The application in a public service generated an expectation of continuity and search by technological means to verify how long the problems would be solved and what the economy came from that deployment.
\end{abstract}

Keywords: Production strategy. Big data. Framework. Public service. Illustrative case. 


\section{INTRODUÇÃO}

Estratégia de produção é o padrão global de decisões e ações que define papel, objetivos e atividades da produção apoiando a estratégia de negócios (SLACK et al., 1995). Esta definição foi ampliada em Slack e Lewis (2002) como um padrão geral das decisões que determina as competências a longo prazo e suas contribuições para a estratégia global, de qualquer tipo de operação, por meio da conciliação dos requisitos de mercado com os recursos de operações. Logo, essa conciliação ficou conhecida como processo ou a forma como a estratégia de operação é formulada. Conteúdo significa o conjunto de decisões que são tomadas (deliberada ou automaticamente) dentro do domínio da estratégia de operações, visando sinergia e harmonização entre visão externa (mercado) e a visão interna (recursos e processos). Relaciona-se com o desempenho requerido via objetivos de desempenho e decisões estratégicas que formatam e desenvolvem a direção da operação a longo prazo, em relação à alocação dos recursos, pelo que é denominado de áreas de decisão.

A visão externa pode ser apoiada pela utilização de Big Data, "um termo genérico para dados que não podem ser contidos nos repositórios usuais; refere-se a dados volumosos demais para caber em um único servidor; não estruturados demais para se adequar a um banco de dados organizado em linhas e colunas; ou fluido demais para serem armazenados em um data warehouse estático" (DAVENPORT, 2014).

O objetivo desse artigo é apresentar uma proposta de framework que dê suporte à estratégia de produção utilizando aspectos de Big Data.

A próxima seção apresenta a revisão da literatura sobre estratégia de produção e Big Data, conceitos e características que comporão o framework proposto, na sequência apresenta-se o método de pesquisa adotado e alguns achados, a proposta é discutida brevemente e uma aplicação em um serviço público será descrita em termos gerais, ao que, as considerações finais são feitas.

\section{ESTRATÉGIA DE PRODUÇÃO: DEFINIÇÃO E CARACTERÍSTICAS PRINCIPAIS}

Há uma hierarquia de estratégias a ser compreendida e foi apresentada por 
Hayes e Wheelwright (1984), Mills, Platts, e Gregory (1995), Hayes et al. (2004), Johnson, Scholes, Whittington (2009), como sendo três partes: i) estratégia corporativa (grupo de empresas), ii) estratégia competitiva ou de negócios (empresa ou unidade de negócios do grupo) e a iii) estratégia funcional (função ou setor, por exemplo produção). Em estratégia competitiva, Porter (1980) propôs cinco forças competitivas (poder de barganha de clientes e fornecedores, concorrentes, ameaça de produtos substitutos e de novos entrantes), podendo ser utilizadas no formato de uma estratégia competitiva genérica (liderança por custo, diferenciação e enfoque).

Hörte, Lindberg, e Tunälv (1987) reforçam que as decisões da estratégia competitiva são baseadas em análise cuidadosa do ambiente e da própria empresa.

Os requisitos de mercado sobre a estratégia de produção tem sua avaliação requerida pelos objetivos de desempenho genéricos (Meyer, Nakane e Ferdows 1989; Hill, 1993; Slack et al., 1995; Slack e Lewis, 2002): qualidade, entrega (velocidade e confiabilidade), flexibilidade e custo. Hill (1995) propôs 5 passos para a formulação da estratégia de produção: i) Passo 1: definição dos objetivos corporativos; ii) Passo 2: definição da estratégia de marketing; iii) Passo 3: definição dos critérios qualificadores e ganhadores de pedidos; iv) Passo 4: escolha do processo para produzir e entregar os produtos; v) Passo 5: definição da infraestrutura necessária.

\section{BIG DATA: DEFINIÇÃO, CONCEITOS E ELEMENTOS ESTRUTURANTES BÁSICOS DE UM FRAMEWORK}

Conforme IDC iView (2011), "Tecnologias de Big Data descrevem uma nova geração de tecnologias e arquiteturas, projetadas para extrair valor economicamente de volumes muito grandes de uma ampla variedade de dados, permitindo a captura, descoberta e / ou análise de alta velocidade". Big data é um conceito abstrato com recursos que o diferencia de dados massivos ou muito grandes (Chen, Mao, Liu, 2014). Para Davenport, Barth e Bean (2012), o termo Big Data é utilizado de forma distorcida por provedores de soluções para classificar sistemas de análise de dados. Afirma-se que é mais do que isso, pois permite o surgimento de novas

possibilidades e serviços, favorecendo as empresas responderem às novas 
demandas de forma mais ágil e mais assertiva, competindo de forma mais eficiente no mercado, tomando melhores decisões de negócio a partir de uma diversidade de fontes de informação combinadas.

As análises de dados do Big Data podem permitir uma abordagem de marketing direcionado que dá à empresa uma melhor compreensão de seus clientes. Um entendimento que influenciará os processos internos e aumentará o lucro, o que proporciona a vantagem competitiva que a maioria das empresas está buscando (ISACA, 2016). Sivarajah et al. (2017) destacam que há alguns desafios acerca das análises de dados do Big Data e os métodos analíticos vigentes, complementado por Kambatla et al. (2014) que apresentam o estado da arte das tendências emergentes de hardware, software e cenário de aplicativos de análise de Big Data.

Chen, Mao, Liu (2014), De Mauro, Greco e Grimaldi (2016), caracterizam os dados em 4 V's: Volume (grande volume disponível), Variedade (várias modalidades e formatos), Velocidade (geração rápida) e Valor (valor enorme para se obter retorno destes investimentos). IBM (2016) acrescenta Veracidade (ter certeza que os dados fazem sentido e são autênticos). O problema mais crítico em Big Data é como descobrir valores de conjuntos de dados com uma escala enorme, vários tipos e geração rápida (Olofson et al., 2016). O alto volume, velocidade e variedade de ativos de informação demandam formas inovadoras e econômicas de processamento de informações para melhor percepção e tomada de decisão (WAMBA et al., 2015; AKTER e WAMBA; 2016). Velocidade de processamento das informações permite a análise instantânea dos dados e possibilita agilidade, e criando-se ofertas de marketing em tempo real para seus consumidores (MCAFEE; BRYNJOLFSSON, 2012). Segundo DAVENPORT, BARTH e BEAN (2012), torna-se necessário considerar o fluxo contínuo de informação e processos, analisando os dados à medida que esses são gerados, ao invés de apenas armazená-los em grandes bancos de dados para análise posterior. Variedade para NOVO (2014) refere-se às diversas fontes de dados: mensagens, leitura de sensores, câmeras de segurança, aparelhos GPS; telefones celulares, RFID, entre outros, que podem ser utilizados para análise e posterior extração de informação. Essas fontes podem englobar desde dados de voz de call centers, até dados de genoma obtidos pelas 
pesquisas biológicas e medicinais, das mais diversas origens, uma copiadora ou um motor a jato (DAVENPORT; BARTH; BEAN, 2012; BROWN; CHUI; MANYIKA, 2011). Veracidade É a qualidade dos dados e informações, essencial para que os usuários interessados (executivos, gestores públicos e sociedade em geral) usem e reusem esses dados de maneira real e apropriada, gerando informações úteis e verídicas para eles mesmos. A verificação dos dados coletados para adequação e relevância ao propósito da análise é um ponto chave para se obter dados que agreguem valor ao processo (HALPER E KRISHNAN, 2014). Valor imediato da maioria dos dados é evidente para aqueles que os coletam, na constatação de MAYER-SCHÖNBERGER e CUKIER (2013), passando de uso primário para uso potencial no futuro, gerando profundas consequências na forma como os negócios valorizam seus dados e a quem conferem acesso a eles. Isso permite e até obrigue as empresas a mudar seus modelos de negócios e alterar a forma como enxergam e utilizam os dados.

Sheng et al. (2017) destacaram a perspectiva multidisciplinar do Big Data destacando que tanto a disponibilidade das informações em várias fontes quanto sua viabilidade de obtenção são condições críticas para um bom processo de tomada de decisão estratégica. Além disso, propuseram um framework em 3 estágios de valor do Big Data cruzados com práticas de gestão em termos de: mudança organizacional, tomada de decisão estratégica e desenvolvimento do negócio. Siddiqa et al. (2016) destacam técnicas de gestão para Big Data e chamam a atenção não só para o armazenamento, pré-processamento e processamento, como também para a segurança dos dados e análises posteriores. Para Agrawal et al. (2011) há um pipeline de análise Big Data composto por 5 fases em fluxo: i) Fase 1: aquisição e registro dos dados; ii) Fase 2: Extração - Limpeza - Anotações sobre os dados; iii) Fase 3: Integração - Agregação - Representação desses dados; iv) Fase 4: Análise e Modelagem; v) Fase 5: Interpretação. Em cada uma dessas Fases há necessidades que tornam essas tarefas desafiadoras. Davenport (2014) apresentou 3 dimensões a serem consideradas na estratégia de implantação e utilização de Big Data: i) Dimensão 1: "focar em um problema!" com sentido duplo: sentido um - do ambiente interno para o Big Data ("situação nova interna - inovação ou alteração que despertaria interesses?") e sentido dois - do Big Data para o 
ambiente interno ("situação nova ou inovação externa - novidades externas que deveríamos ter conhecimento?"; ii) Dimensão 2: matriz de objetivos e estágios de aplicação. Objetivos de valor a partir do Big Data: baixar custos, decisões mais rápidas (tempo), decisões melhores (foco - objetividade), inovação de produto ou serviço. Estágios de aplicação: descobertas (o que? Quem?) e produção (o que? Quem?); iii) Dimensão 3: Rapidez \& Agressividade em relação à concorrência para adotar o Big Data (propõe analisar 3 situações: Conservador? Moderadamente agressivo? Muito agressivo?).

\section{MÉTODO DE PESQUISA}

Foram realizadas três etapas metodológicas: i) pesquisa bibliográfica; ii) elaboração de um framework teórico-conceitual (BD-ProdStrateg) em 5 passos; e iii) aplicação do framework proposto (BD-ProdStrateg).

Etapa 1: a etapa da pesquisa bibliográfica foi realizada em 6 passos, a saber: $1^{\circ}$ Passo: Definição de strings de busca

Foram definidas as seguintes strings de busca, a estratégia de busca nessas strings também foram definidas e o montante de artigos encontrados foram registrados na Tabela 1.

Tabela 1 - overview das strings de busca.

\begin{tabular}{lllll}
\hline \multicolumn{2}{l}{ String de busca I } & String de busca II & String de busca III & String de busca IV \\
\hline $\begin{array}{l}\text { big data AND } \\
\text { framework }\end{array}$ & $\begin{array}{l}\text { big data AND } \\
\text { operations strategy data (título), } \\
\text { figmework (qualquer) }\end{array}$ & $\begin{array}{l}\text { big data AND } \\
\text { manufacturing strategy } \\
\text { operations } \\
\text { strategy(qualquer) }\end{array}$ & $\begin{array}{l}\text { big data (título), } \\
\text { manufacturing } \\
\text { strategy(qualquer) }\end{array}$ & $\begin{array}{l}\text { big data (título), } \\
\text { strategy(qualquer) }\end{array}$ \\
714 artigos & 235 artigos & 79 artigos & 464 artigos \\
\hline
\end{tabular}

Fonte: elaborada pelos autores

Para esse Passo 1 foram utilizados três filtros de pesquisa: i) período: dos últimos 10 anos: 2007 a 2017; ii) tipo de publicação: somente artigos; iii) artigos revisados por pares.

2 Passo: elaboração das 7 principais bases de dados que mais tinham publicações de artigos nessa temática (Figura 1). 
Figura 1 - Top 7 das Bases de Dados pesquisadas e resultados das buscas.

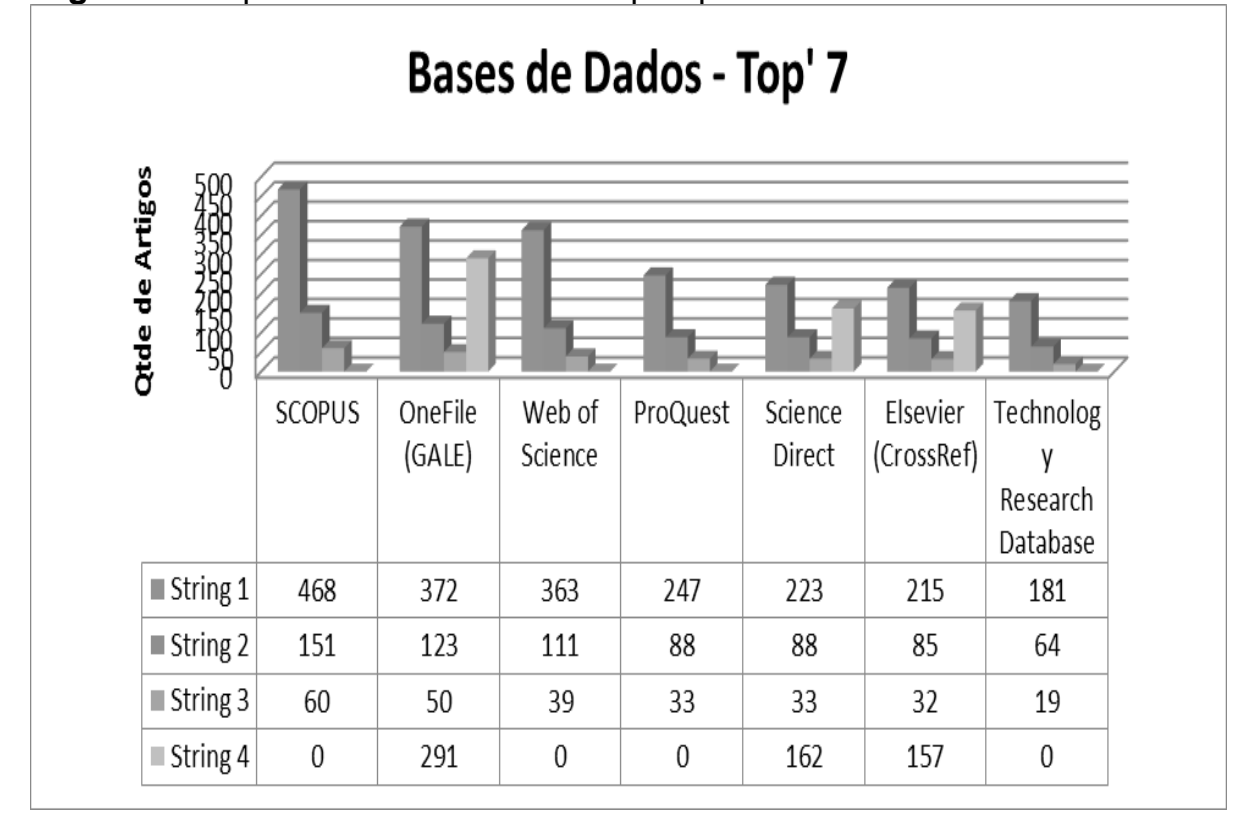

Fonte: elaborado pelos autores

3o Passo: elaboração dos 12 principais periódicos que mais tinham publicações de artigos nessa temática (Tabela 2)

Tabela 2 - Top 12 periódicos com maior número de publicações

\begin{tabular}{|c|c|c|c|c|c|}
\hline Periódicos & string 1 & string 2 & string 3 & string 4 & Total \\
\hline Big Data \& Society & 30 & 14 & 0 & 32 & 76 \\
\hline Big Data \&Amp; Society & 33 & 14 & 0 & 32 & 79 \\
\hline $\begin{array}{c}\text { Future Generation Computer } \\
\text { Systems }\end{array}$ & 14 & 8 & 3 & 10 & 35 \\
\hline $\begin{array}{l}\text { International Journal of } \\
\text { Production Economics }\end{array}$ & 12 & 8 & 7 & 9 & 36 \\
\hline Knowledge-Based Systems & 11 & 6 & 0 & 12 & 29 \\
\hline Journal of Business Research & 8 & 6 & 2 & 9 & 25 \\
\hline Information Sciences & 11 & 3 & 1 & 7 & 22 \\
\hline Plos One & 9 & 0 & 2 & 9 & 20 \\
\hline $\begin{array}{c}\text { Industrial Management \& Data } \\
\text { Systems }\end{array}$ & 7 & 4 & 2 & 5 & 18 \\
\hline $\begin{array}{c}\text { Mathematical Problems in } \\
\text { Engineering }\end{array}$ & 6 & 2 & 0 & 7 & 15 \\
\hline $\begin{array}{c}\text { International Journal Of } \\
\text { Distributed Sensor Networks }\end{array}$ & 0 & 5 & 0 & 10 & 15 \\
\hline Cluster Computing & 0 & 5 & 2 & 7 & 14 \\
\hline
\end{tabular}

Fonte: elaborada pelos autores 
4ํ Passo: os nove principais autores que publicaram nessa temática (Tabela 3).

Destaque-se que o critério foi ter pelo menos publicações encontradas em três das strings de busca e quando houvesse somente em duas strings privilegiou-se a string 2 e string 4 devido ao recorte temático buscado.

Tabela 3 - Top 9 autores que publicaram na temática

\begin{tabular}{cccccc}
\hline Autores & string 1 & string 2 & string 3 & string 4 & Total \\
\hline Akter, Shahriar & 4 & 5 & 4 & 5 & 18 \\
Wamba, Samuel Fosso & 0 & 5 & 4 & 6 & 15 \\
Gunasekaran, Angappa & 4 & 3 & 3 & 4 & 14 \\
Wang, Lizhe & 0 & 4 & 0 & 7 & 11 \\
Ranjan, Rajiv & 0 & 4 & 0 & 6 & 10 \\
Dubey, Rameshwar & 3 & 0 & 2 & 3 & 8 \\
Chen, Jinjun & 0 & 3 & 0 & 5 & 8 \\
Herrera, Francisco & 0 & 3 & 0 & 4 & 7 \\
Triguero, Isaac & 0 & 3 & 0 & 4 & 7 \\
\hline
\end{tabular}

Fonte: elaborada pelos autores.

5० Passo: análise e seleção dos artigos dos nove principais autores

Nesse passo foi realizada a leitura e análise dos artigos levantados no Passo 4, com um recorte adicional dos nove primeiros autores (Akter, Dubey, Gunasekaran e Wamba) mais encontrados nas buscas. Foi considerado o resumo, introdução e conclusão dos artigos. Após esse procedimento houve uma decisão de seleção do artigo e passou-se a registrar algumas informações a seu respeito. O Quadro 1 apresenta uma síntese do registro dos trabalhos desses nove autores mais incidentes selecionados na busca. 
Quadro 1 - síntese dos artigos dos 9 autores selecionados nas 4 buscas

(continua)

\begin{tabular}{|c|c|c|c|}
\hline Autor (ano) & Título do Artigo & Objetivo do Artigo & Aspectos Relevantes \\
\hline Wamba et al. (2015) & $\begin{array}{l}\text { How 'big data' can make big } \\
\text { impact: findings from a } \\
\text { systematic review and a } \\
\text { longitudinal case study }\end{array}$ & \begin{tabular}{llr} 
Apresentar & uma & \multicolumn{2}{r}{ estrutura } \\
interpretativa que analisa & as \\
perspectivas de definição e as \\
aplicações de Big Data
\end{tabular} & $\begin{array}{l}\text { - revisão sistemática } \\
\text { - estudo de caso longitudinal } \\
\text { - Big Data genérico } \\
\text { - eco-sistema de informação } \\
\text { - insights críticos e tomada de decisão. }\end{array}$ \\
\hline $\begin{array}{l}\text { Liu; Yang; Zhang; Chen, } \\
\text { Jinjun (2015) }\end{array}$ & $\begin{array}{l}\text { External integrity verification for } \\
\text { outsourced big data in cloud and } \\
\text { loT: A big picture }\end{array}$ & $\begin{array}{l}\text { Apresentar um panorama geral ao } \\
\text { fornecer uma análise das técnicas de } \\
\text { verificação de integridade de dados } \\
\text { baseadas em autenticador em dados } \\
\text { de nuvem e Internet das Coisas. }\end{array}$ & $\begin{array}{l}\text { - Como a computação em nuvem está sendo } \\
\text { amplamente adotada para o processamento de big data, } \\
\text { a segurança de dados está se tornando uma das } \\
\text { principais preocupações dos proprietários de dados. } \\
\text { - A integridade dos dados é um fator importante em } \\
\text { quase todos os contextos relacionados a dados e } \\
\text { computação. } \\
\text { Não é apenas uma das qualidades do serviço, mas } \\
\text { também uma parte importante da segurança e } \\
\text { privacidade dos dados. } \\
\text { - Com a proliferação da computação em nuvem e as } \\
\text { crescentes necessidades em análise de big data, como } \\
\text { os dados gerados pela Internet of Things, a verificação } \\
\text { da integridade dos dados torna-se cada vez mais } \\
\text { importante, especialmente em dados terceirizados. }\end{array}$ \\
\hline Dubey et al. (2016) & $\begin{array}{l}\text { The impact of Big Data on } \\
\text { world-class } \\
\text { manufacturing }\end{array}$ & $\begin{array}{l}\text { llustrar o papel da Análise Big Data no } \\
\text { suporte à manufatura sustentável de } \\
\text { classe mundial }\end{array}$ & $\begin{array}{l}\text { - WCSM framework e seus indicadores } \\
\text { - framework a partir da literatura revisada } \\
\text { - propriedades psicométricas dos itens de medição do } \\
\text { instrumento desenvolvido. }\end{array}$ \\
\hline Akter e Wamba (2016) & $\begin{array}{l}\text { Big Data Analytics in e- } \\
\text { commerce: a systematic review } \\
\text { and agenda for future research }\end{array}$ & $\begin{array}{l}\text { Explorar e dar um posicionamento do } \\
\text { uso de Big Data no e-commerce com } \\
\text { base em revisão sistemática da } \\
\text { literatura }\end{array}$ & $\begin{array}{l}\text { - desafios do BDA no comércio eletrônico. } \\
\text { - aplicações de análise transversais no comércio } \\
\text { eletrônico. }\end{array}$ \\
\hline $\begin{array}{lr}\text { Wang, } & \text { Gunasekaran, } \\
\text { Ngai, } & \text { Papadoulos } \\
(2016) & \end{array}$ & $\begin{array}{l}\text { Big data analytics in logistics } \\
\text { and supply chain management: } \\
\text { certain investigations for } \\
\text { research and applications }\end{array}$ & $\begin{array}{l}\text { Revisar e classificar a literatura de } \\
\text { aplicação do Big Data business } \\
\text { analytics na logística e na gestão da } \\
\text { cadeia de suprimentos. }\end{array}$ & $\begin{array}{l}\text { - proposta de framework de maturidade de Supply Chain } \\
\text { Analytics (SCA). } \\
\text { - framework em cinco níveis de capabilidade } \\
\text { (estratégica e operacional) }\end{array}$ \\
\hline $\begin{array}{l}\text { Akter, Wamba, } \\
\text { Gunasekaran, Dubey e } \\
\text { Childe (2016) }\end{array}$ & $\begin{array}{l}\text { How to improve firm } \\
\text { performance using big data } \\
\text { analytics capability and } \\
\text { business strategy alignment? }\end{array}$ & $\begin{array}{l}\text { Proposta de um modelo BDAC (big } \\
\text { data analytics capability) projetado } \\
\text { com a teoria da visão baseada em } \\
\text { recursos (RBT) e a visão emaranhada } \\
\text { do sociomaterialismo }\end{array}$ & $\begin{array}{l}\text { - Big Data compensa para algumas empresas mas } \\
\text { poucas conseguiram algo significativo e de impacto. } \\
\text { - } 2 \text { estudos Delphi } \\
\text { - } 152 \text { surveys online (analistas de negócios) } \\
\text { - propuseram um modelo estrutural hierárquico BDAC }\end{array}$ \\
\hline
\end{tabular}

Revista Produção Online. Florianópolis, SC, v. 20, n. 1, p. 47-62, 2020 
Quadro 1 - síntese dos artigos dos 9 autores selecionados nas 4 buscas

\begin{tabular}{|c|c|c|c|}
\hline & & & \\
\hline Autor (ano) & Título do Artigo & Objetivo do Artigo & Aspectos Relevantes \\
\hline $\begin{array}{l}\text { Wamba, Gunasekaran, } \\
\text { Akter, Ren, Dubey e } \\
\text { Childe (2017) }\end{array}$ & $\begin{array}{l}\text { Big Data analytics and firm } \\
\text { performance: effects of } \\
\text { dynamic capabilities }\end{array}$ & $\begin{array}{l}\text { Proposta de extensão do modelo BDAC } \\
\text { (big data analytics capability) analisando } \\
\text { tanto a performance de empresas } \\
\text { (financeira e mercado) quanto as } \\
\text { capacidades dinâmicas orientadas a } \\
\text { processos (PODC). }\end{array}$ & $\begin{array}{l}\text { - } 297 \text { surveys online envolvendo analistas de negócios e } \\
\text { gestores de TI chineses com experiência em Big Data. } \\
\text { - } 3 \text { hipóteses } \mathrm{H} 1, \mathrm{H} 2 \text { e H3, sobre os efeitos do BDAC. } \\
\text { - os achados confirmaram o valor do "conceito de } \\
\text { emaranhamento" do modelo hierárquico BDAC }\end{array}$ \\
\hline 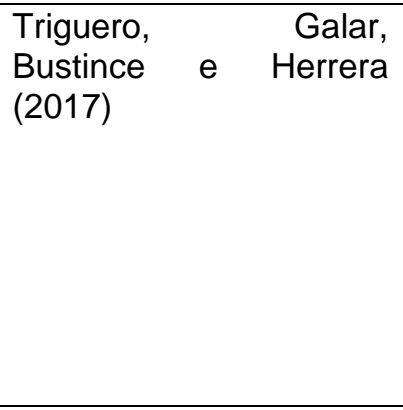 & $\begin{array}{l}\text { A First Attempt on Global } \\
\text { Evolutionary Undersampling } \\
\text { for } \\
\text { Imbalanced Big Data }\end{array}$ & $\begin{array}{l}\text { uma primeira tentativa no projeto de um } \\
\text { modelo evolutivo de subamostragem } \\
\text { global para problemas de classificação } \\
\text { desequilibrados. } \\
\text { Estes são caracterizados por ter uma } \\
\text { distribuição altamente distorcida de } \\
\text { classes em que os modelos evolutivos } \\
\text { estão sendo usados para balancear o } \\
\text { conjunto de dados selecionando apenas } \\
\text { os dados mais relevantes. }\end{array}$ & $\begin{array}{l}\text { Utilizando o Apache Spark como tecnologia de big data, } \\
\text { introduzimos várias variações no conhecido algoritmo } \\
\text { CHC para trabalhar com cromossomos muito grandes e } \\
\text { reduzir os custos associados à avaliação da aptidão. } \\
\text { Discutimos alguns resultados preliminares, mostrando o } \\
\text { grande potencial desse novo tipo de modelo evolutivo } \\
\text { de Big Data. }\end{array}$ \\
\hline
\end{tabular}

Fonte: Elaborado pelos autores 
Etapa 2: elaboração de um framework teórico-conceitual (BD-ProdStrateg) foi realizada em 5 passos descritos de modo geral na sequência e que serão detalhados na seção de Resultados e Discussão.

- Passo 1 - Compreensão do framework de estratégia de operações combinando as propostas de Slack et al. (2015), Slack e Lewis (2002), e complementando com Chase; Jacobs e Aquilano (2003).

- Passo 2 - Pesquisas acerca de frameworks que operacionalizam Big Data de modo geral.

- Passo 3 - Busca de oportunidades de utilização do Big Data no framework do Passo 1.

- Passo 4 - Elaboração de framework híbrido a partir das pesquisas e das oportunidades encontradas.

- Passo 5 - Apresentação de um framework teórico-conceitual para utilização e suporte à estratégia de produção, intitulado BDProdStrateg.

Etapa 3: uma aplicação de ilustração do framework teórico-conceitual (BDProdStrateg) foi realizada em um Serviço Público de Tratamento de Água e Esgoto Municipal que atende uma cidade com população em torno de 250.000 habitantes.

Esse Serviço Público tem uma série de demandas e canais de atendimento. Sendo assim, identificou-se a oportunidade de se aplicar o framework BDProdStrateg devido às diversas fontes de informações possíveis de serem analisadas e aos vários problemas relacionados com os serviços prestados, visando melhorias sensíveis a partir da indicação de prioridades e focos da ação operacional.

Há uma demanda mensal média em torno de 350 chamadas (domésticascalçadas e vias públicas) que são atendidas no curto, médio e longo prazo, uma média de 10 a 15 novos vazamentos por dia. Os vazamentos de maior porte em redes primárias e os de menor, em redes secundárias.

As metas de 2017: i) atendimento no mínimo de 20 vazamentos/dia e solução dos problemas em definitivo; ii) zerar os vazamentos na cidade; iii) atender e reduzir as reclamações por problema na marcação do hidrômetro, cobrança de conta errada, solicitação de instalação/troca de hidrômetro; e outros motivos que se enquadram em exceções e tem um direcionamento feito pelo corpo técnico. 
Por diversos motivos, além dos vazamentos aparentes, há uma perspectiva que em torno de $45 \%$ da água tratada se esvai pela rede primária e secundária, principalmente, por vazamentos ocultos espalhados pela cidade que podem levar um bom tempo até serem detectados, pois, a tubulação é bem antiga, com mais de 30 anos. Há uma intenção de desenvolver ações para coibir essas perdas.

\section{RESULTADOS E DISCUSSÃO}

Os 5 passos da Etapa 2, que elaborou o framework teórico-conceitual (BDProdStrateg), são na sequência detalhados.

- Passo 1 - Compreensão do framework de estratégia de operações proposto por Slack et al. (2015), Slack e Lewis (2002), complementado por Chase; Jacobs e Aquilano (2003).

Quatro grandes blocos foram analisados por esses autores a serem considerados na estratégia de operações (ou produção), são eles: i) requisitos de mercado (desempenho requerido para atuar); ii) recursos de operações (decisões estratégicas, competências e processos); iii) interpretação da estratégia do nível mais alto (corporativo e negócio); iv) experiência operacional (sentido emergente do que a estratégia deveria ser).

- Passo 2 - Pesquisas acerca de frameworks que operacionalizam Big Data de modo geral.

Foram encontrados alguns frameworks: CRM analítico via Big Data (LIU, 2015), gestão da inovação em serviços intensivos em conhecimento (CAMPOS, 2015), Big Data para patentes (SEO; KIM; e CHOI, 2014), cujo objetivo é apoiar o planejamento estratégico de P\&D, e Big Data analítico interligando um modelo teórico de orientação de mercado e Visão Baseada em Recursos (RBV) aliado à Visão Baseada em Conhecimento (KBV) (JELINEK e BERGEY, 2013).

- Passo 3 - Busca de oportunidades de utilização do Big Data a partir do Passo 1

A partir do Passo 1, analisando-se os quatro grandes blocos, identificaram-se algumas oportunidades de incursão do Big Data nos processos decisórios de 
planejamento e operacionalização relacionados com a estratégia de operações (ou produção) (Quadro 2).

Quadro 2 - oportunidades de incursão de Big Data na estratégia de produção

\begin{tabular}{|l|l|}
\hline \multicolumn{1}{|c|}{ Aspectos da Estratégia de Produção } & \multicolumn{1}{|c|}{ Oportunidades de Incursão de Big Data } \\
\hline Requisitos de mercado & $\begin{array}{l}\text { - Análises para avaliar desempenho de produtos } \\
\text { e serviços; }\end{array}$ \\
& $\begin{array}{l}\text { - CRM analítico para identificação de novas } \\
\text { necessidades dos já clientes - marketing ativo; } \\
\text { - Análises de novos clientes em potencial - } \\
\text { marketing prospectivo; } \\
\text { - Análises da concorrência em relação a produtos } \\
\text { e serviços existentes ou novos lançamentos. }\end{array}$ \\
\hline Recursos de operações & $\begin{array}{l}\text { Informações em relação a procurement e } \\
\text { homologação de novos fornecedores }\end{array}$ \\
\hline Interpretação da estratégia de mais alto nível & $\begin{array}{l}\text { - análises em relação ao que foi feito e deu certo, } \\
\text { a novas tendências, a inovações, diretrizes para } \\
\text { novos projetos e novas estratégias. }\end{array}$ \\
\hline Experiência operacional & $\begin{array}{l}\text { - dinâmica das lições aprendidas com todas as } \\
\text { informações captadas e conhecimento adquirido } \\
\text { com as análises de dados do Big Data }\end{array}$ \\
\hline
\end{tabular}

Fonte: elaborado pelos autores

- Passo 4 - Elaboração de framework híbrido a partir das pesquisas e das oportunidades encontradas.

A partir do levantamento feito uma tendência ficou comprovada: é preciso buscar a simplicidade, a regularidade de análise, em meio ao caos e à diversidade de fontes de dados do Big Data. Também, outra constatação, é que não há um impeditivo tecnológico devido às várias possibilidades existentes dependendo exclusivamente "DO QUE" se necessita analisar ou pesquisar no Big Data. Daí a importância do Modelo de Análise de Dados (ou Data Model), que é o centro de todo o processo decisório decorrente a partir dele. Ou seja, se esse Modelo de Análise de Dados for inadequado então o resultado será inadequado.

A partir da adaptação das 5 Fases de Agrawal et al. (2011) chega-se a um esquema geral (Quadro 3). 
Quadro 3 - Visão geral das camadas de composição de um framework de Big Data.

\begin{tabular}{|l|l|l|l|}
\hline \multicolumn{1}{|c|}{ FASES } & \multicolumn{1}{|c|}{ Objetivo da Fase } & \multicolumn{1}{c|}{$\begin{array}{c}\text { Características dos } \\
\text { Dados }\end{array}$} & Camada do Pipeline \\
\hline FASE I & Aquisção e registro & Incompleteza dos dados & $\begin{array}{l}\text { Camada de Fonte de } \\
\text { Dados }\end{array}$ \\
\hline FASE II & Extração, limpeza e anotações & Dados em escala & Camada ETL \\
\hline FASE III & $\begin{array}{l}\text { Integração, agregação e } \\
\text { representação }\end{array}$ & Temporalidade dos dados & $\begin{array}{l}\text { Camada } \\
\text { Armazenagem }\end{array}$ \\
\hline FASE IV & Análise e modelagem & $\begin{array}{l}\text { Privacidade dos dados e } \\
\text { origens das fontes }\end{array}$ & Camada de análise \\
\hline FASE V & interpretação & $\begin{array}{l}\text { Colaboração humana para } \\
\text { análise e interpretação } \\
\text { dos dados }\end{array}$ & Cama de usuários \\
\hline
\end{tabular}

Fonte: elaborado pelos autores.

Adaptando-se também a estratégia de Big Data pelas Dimensões mencionadas por Davenport (2014), chega-se a algumas considerações relevantes, ilustradas no Quadro 4.

Quadro 4 - Adaptação da estratégia de Big Data nas Dimensões propostas por Davenport (2014)

\begin{tabular}{|c|c|c|}
\hline \multirow[t]{2}{*}{ Dimensão 1} & \multirow[t]{2}{*}{$\begin{array}{l}\text { Foco no problema analisando-o } \\
\text { em dois sentidos }\end{array}$} & $\begin{array}{l}\text { Sentido 1: captar do Big Data } \\
\text { Problema de inovação ou } \\
\text { alteração de produto ou } \\
\text { serviços internos? } \\
\text { (situação nova interna) }\end{array}$ \\
\hline & & $\begin{array}{l}\text { Sentido 2: tratar dados do Big } \\
\text { Data } \\
\text { Problema de novidades } \\
\text { externas concorrenciais? } \\
\text { (situação externa nova ou } \\
\text { inovação) }\end{array}$ \\
\hline Dimensão 2 & $\begin{array}{l}\text { Matriz de objetivo e estágios de } \\
\text { aplicação } \\
\text { produção) }\end{array}$ & $\begin{array}{l}\text { Adaptação dessa Matriz com } \\
\text { aspectos da Estratégia } \\
\text { Competitiva de Porter (1980) e } \\
\text { os passos } 1 \text { e 2, do Modelo de } \\
\text { Hill (1995). }\end{array}$ \\
\hline Dimensão 3 & $\begin{array}{l}\text { Rapidez e Agressividade das } \\
\text { implantações de projetos Big } \\
\text { Data }\end{array}$ & $\begin{array}{l}\text { Adaptação de critérios de } \\
\text { decisão a partir de Paiva, } \\
\text { Carvalho Jr., Fensterseifer } \\
\text { (2009) no conjunto das } \\
\text { atividades da Rede de Valor e } \\
\text { Operações (RVO). }\end{array}$ \\
\hline
\end{tabular}

Fonte: Elaborado pelos autores.

É necessário fazer uma consideração a partir dos 5V's do Big Data propondo uma tabulação geral das fontes e suas possíveis características para direcionar a utilização de ferramentas/aplicativos específicos conforme o caso e a necessidade do Modelo de Análise de Dados. 
No Quadro 5, a Matriz 5V's, apresenta-se a visão geral das fontes e formatos de dados, a partir da aplicação no Serviço Público e, pelo fato de haver uma diversidade de ferramentas computacionais, elas não foram mencionadas neste quadro propositalmente, pois isto depende do problema a ser pesquisado no Big Data.

- Passo 5 - Apresentação de um framework teórico-conceitual para utilização e suporte à estratégia de produção.

O formato geral do framework proposto (Figura 2) envolve decisões dos 3 níveis hierárquicos - estratégico, operacional e técnico - ao identificar os aspectos de Preparação e Satisfação, utiliza 5 fases do pipeline (Fase l a V) e diferencia 5 camadas para cada uma dessas fases (Fonte de dados, ETL, Armazenagem, Análise, Usuários). Nos aspectos de Preparação e Satisfação são mencionados os conceitos afins ao uso de informações do Big Data e em que elas devem se enquadrar enquanto Dimensões, Passos e Conjunto de ações da RVO.

Figura 2 - overview da proposta de framework teórico-conceitual

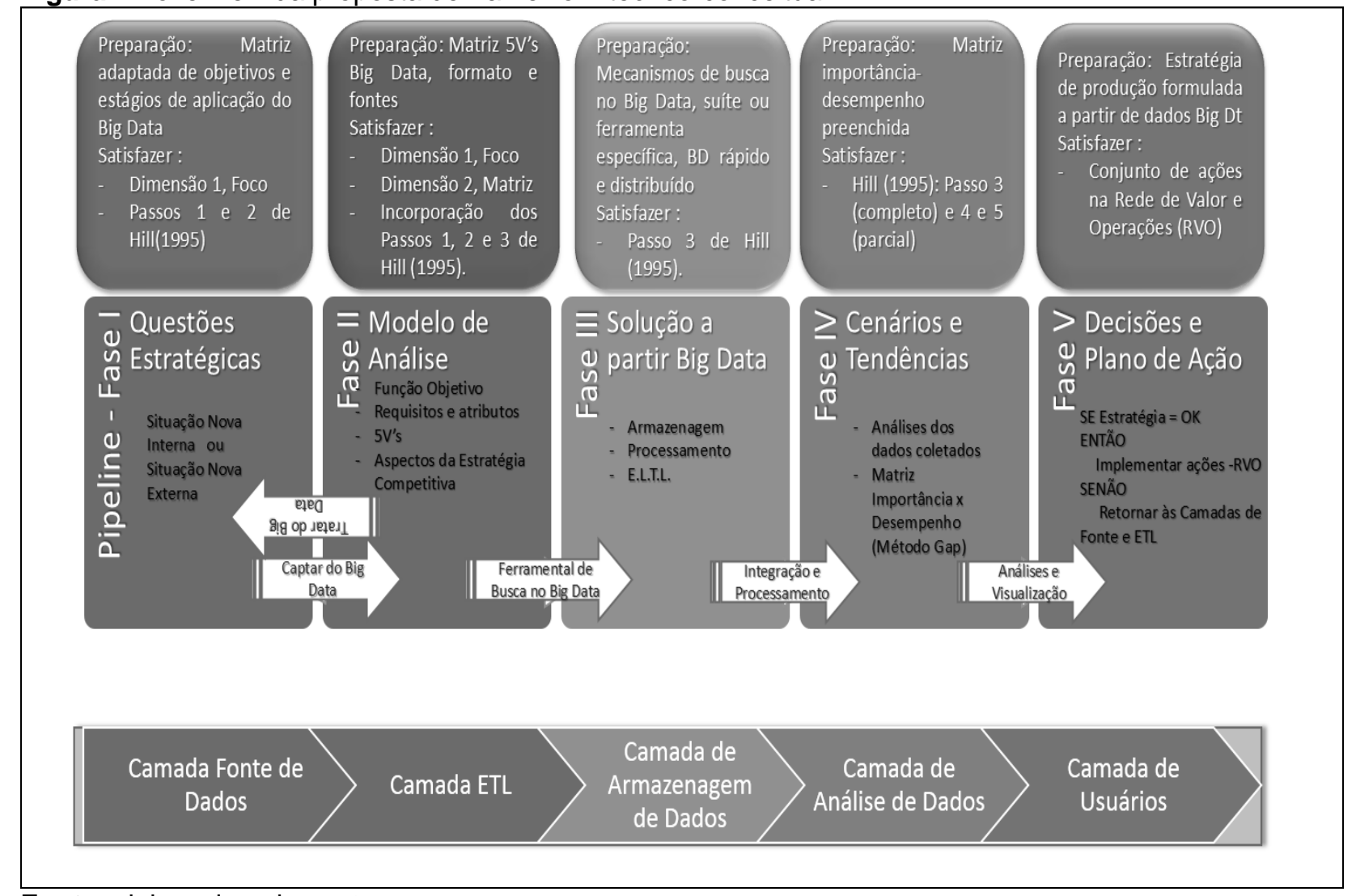

Fonte: elaborado pelos autores 


\section{ETAPA 3: ILUSTRAÇÃO DE APLICAÇÃO DO FRAMEWORK NO SERVIÇO PÚBLICO}

Para esta ilustração de aplicação no Serviço Público, utilizou-se a atuação da Gerência de Operações e Serviços (GOS) que é composta pelo: SO - setor de obras, SMR - setor de manutenção de redes e SCP - setor de controle de perdas.

O framework se inicia pela FASE I-Questões Estratégicas, definindo-se na Dimensão 1 o Foco da aplicação (sentido interno, ou seja, com a mesma equipe e os mesmos recursos disponíveis buscar ser mais assertivo nos reparos estendendo à rede as intervenções) - dar um sentido novo interno a partir das informações do Big Data. O Foco pretendido é seguir a meta anunciada pela presidência do Serviço Público de que em 2018 os vazamentos estarão zerados em sua totalidade.

Passos de Hill (1995): Passo 1 - definição de objetivos corporativos em relação a suprimentos, serviços, produção, distribuição e serviços agregados, ou seja, extinção dos vazamentos e renovação gradativa da rede primária e secundária.

Passo 2 - definição da estratégia de marketing no sentido de estimular a participação dos contribuintes nos canais de comunicação com a Autarquia visando um pronto atendimento com qualidade e excelência no serviço prestado pela extinção dos vazamentos e pela renovação da rede primária e secundária.

\section{FASE II - Modelo de Análise}

Função objetivo: identificar com a maior rapidez possível os maiores vazamentos, que dependem de equipe multidisciplinar especializada maior e identificando se aquele trecho da rede já foi atualizado (tubulação central reformada com todas as ramificações reformadas e religadas).

Requisitos e atributos: frequência de repetição das informações dos contribuintes cruzando-se com a gravidade do vazamento no resultado geral da rede primária e secundária. 
Quadro 5 - Matriz 5V's versus formato e fonte de dados do Big Data.

\begin{tabular}{|c|c|c|c|c|c|c|c|c|c|c|}
\hline \multirow{2}{*}{$\begin{array}{l}\text { formato } \\
\text { fonte } \\
\text { 5V's }\end{array}$} & \multicolumn{3}{|c|}{ Estruturado } & \multicolumn{3}{|c|}{ Semi Estruturado } & \multicolumn{4}{|c|}{ Não Estruturado } \\
\hline & 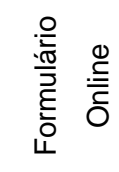 & 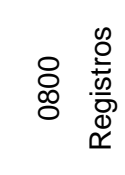 & 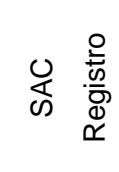 & 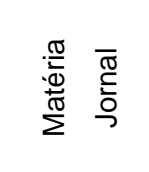 & 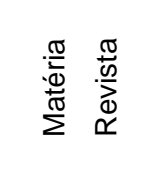 & 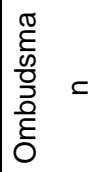 & $\begin{array}{l}\frac{0}{\frac{0}{2}} \\
\frac{0}{\pi} \\
\frac{0}{3}\end{array}$ & 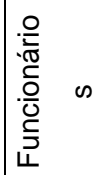 & $\begin{array}{l}\overline{\widetilde{\sigma}} \\
\frac{5}{0} \\
\stackrel{0}{0} \\
\frac{0}{0} \\
-\end{array}$ & 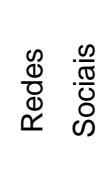 \\
\hline Volume & $15 \%$ & $10 \%$ & 532/ano & 10/ano & 1/ano & $\mathrm{N} / \mathrm{A}$ & $\mathrm{N} / \mathrm{A}$ & $35 \%$ & 15/ano & 60/ano \\
\hline Variedade & alta & alta & alta & específica & específica & alta & $\mathrm{N} / \mathrm{A}$ & alta & específica & alta \\
\hline Velocidade & $24 \mathrm{~h}$ & $24 \mathrm{~h}$ & $24 \mathrm{~h}$ & $\mathrm{~N} / \mathrm{A}$ & $\mathrm{N} / \mathrm{A}$ & $24 \mathrm{~h}$ & $\mathrm{~N} / \mathrm{A}$ & $<\mathrm{t}$ & $\mathrm{N} / \mathrm{A}$ & $24 \mathrm{~h}$ \\
\hline Veracidade & $X$ & $\mathrm{X}$ & $\mathrm{X}$ & $? ?$ & $? ?$ & $\mathrm{X}$ & $? ?$ & $\mathrm{X}$ & $? ?$ & $\mathrm{X}$ \\
\hline Valor & $\mathrm{X}$ & $\bar{X}$ & $\bar{X}$ & & & & & $\mathrm{X}$ & & $\mathrm{X}$ \\
\hline $\begin{array}{l}\text { Ferramentas } \\
\text { Big Data }\end{array}$ & & ${ }^{\star \star}$ ferrar & tas espec & cas de ext & ão, carga, t & nsfor & Ça /I & npeza, & ova carga & \\
\hline
\end{tabular}

Fonte: elaborado pelos autores.

Aspectos da estratégia competitiva: cada vez que for identificado um vazamento de grande proporção deverá ser feita uma análise se é possível ajustar a rede ao longo de 100 metros. Isso implica na possível reforma e religação de fornecimento de residências, estabelecimentos comerciais e de serviços.

Essas implicações devem ser analisadas, se for possível realizar essa renovação de 100 metros nesse serviço de correção de vazamento grande, ao longo de uma semana, pode-se projetar que a cada 10 intervenções isso fosse possível, com essa equipe multidisciplinar especializada, então significa que ao longo de 1 mês poder-se-ia renovar cerca de $4.400 \mathrm{~km} / \mathrm{ano}$, considerando que em dezembro há muita chuva o que dificultaria esse trabalho.

A Dimensão 2 prevê uma matriz cruzando objetivos de valor a partir do Big Data no contexto de uma estratégia genérica com os estágios de aplicação identificando possíveis Descobertas e planejando sua Produção.

A matriz do Quadro 6 ilustra essa dimensão 2 com esses cruzamentos. 
Quadro 6 - Dimensão 2 - Matriz de Objetivos e Estágios de Aplicação a partir do Big Data (continua)

\begin{tabular}{|c|c|c|c|c|c|}
\hline \multirow{2}{*}{$\begin{array}{l}\text { Estratégia } \\
\text { Competitiva }\end{array}$} & \multirow{2}{*}{$\begin{array}{l}\text { Estágios } \\
\text { Aplicaçào } \\
\text { Objetivos } \\
\text { de valor }\end{array}$} & \multicolumn{2}{|c|}{ DESCOBERTAS } & \multicolumn{2}{|c|}{ PRODUÇẪO } \\
\hline & & O que? & Quem? & O que? & Quem? \\
\hline \multirow[b]{2}{*}{$\begin{array}{l}\text { Do } \\
\text { o } \\
\text { ? } \\
0\end{array}$} & Baixar Custos & $\begin{array}{l}\text { - identificação do } \\
\text { problema a tratar } \\
\text {-melhores práticas } \\
\text {-materiais alternativos } \\
\text {-novos esquemas de } \\
\text { treinamento } \\
- \text { desenvolvimento de } \\
\text { kits de reparo e } \\
\text { dispositivos } \\
\text {-ideias dos contribuintes }\end{array}$ & 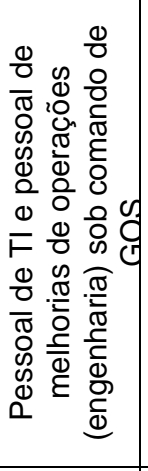 & 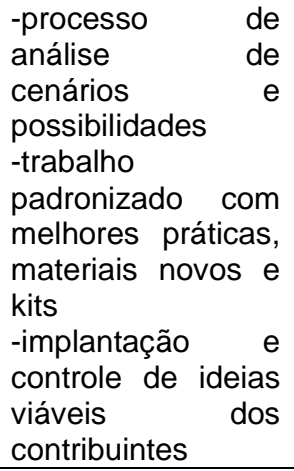 & $\begin{array}{l}\sum_{\infty}^{\mathbb{1}} \\
\infty \\
\stackrel{\infty}{\infty}\end{array}$ \\
\hline & $\begin{array}{l}\text { Decisões } \\
\text { Rápidas } \\
\text { (menor Tempo) }\end{array}$ & $\begin{array}{l}\text { - coletas de dados } \\
\text { focadas nos principais } \\
\text { problemas ocorridos } \\
\text { analisando-os rom } \\
\text { rapidez gerando planos } \\
\text { de ação } \\
\text { investimentos busca de } \\
\text { invernativos com foco } \\
\text { nos objetivos } \\
\text { estratégicos sistematização do } \\
\text { workflow da informação } \\
\text { coletada x decisão }\end{array}$ & 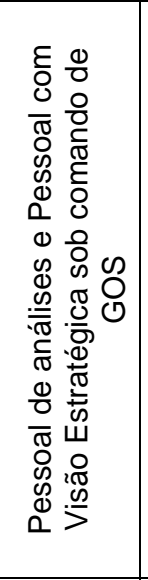 & $\begin{array}{l}\text { operacionalização } \\
\text { dos principais } \\
\text { problemas } \\
\text { elencados nos } \\
\text { planos de ação } \\
\text { - utilização dos } \\
\text { investimentos } \\
\text { alternativos } \\
\text { - utilização do novo } \\
\text { workflow da } \\
\text { informação da da } \\
\text { coletada e da do a } \\
\text { decisão tomada a } \\
\text { partir dela }\end{array}$ & 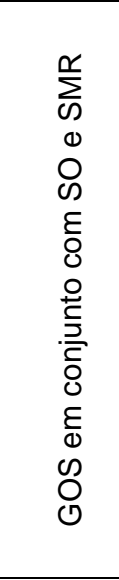 \\
\hline $\begin{array}{l}\text { O } \\
\text { O } \\
\text { ४ }\end{array}$ & $\begin{array}{l}\text { Decisões } \\
\text { melhores } \\
\text { (foco } \\
\text { objetividade) } \\
\text { (maior } \\
\text { assertividade) }\end{array}$ & $\begin{array}{l}\text { - diversidade de dados } \\
\text { coletados x cenários } \\
\text { analisados } \\
\text { - séries históricas dos } \\
\text { principais problemas } \\
\text { nas principais regiões } \\
\text { da cidade } \\
\text { - análise das tendências } \\
\text { das preincipais } \\
\text { providências e planos } \\
\text { de ação x resultados }\end{array}$ & 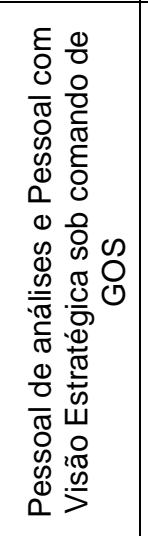 & $\begin{array}{l}\text { - cenários } \\
\text { analisados } \\
\text { gerando ações de } \\
\text { melhorias nas } \\
\text { operações atuação } \\
\text { - direcionada para } \\
\text { determinados } \\
\text { problemas em } \\
\text { determinadas } \\
\text { regiões } \\
\text { - sistematização do } \\
\text { feedback dos } \\
\text { planos } \\
\text { desenvolvidos }\end{array}$ & 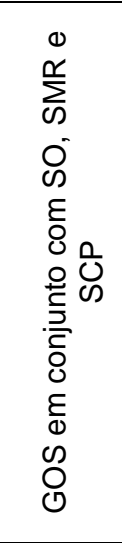 \\
\hline
\end{tabular}

Revista Produção Online. Florianópolis, SC, v. 20, n. 1, p. 47-62, 2020 
Quadro 6 - Dimensão 2 - Matriz de Objetivos e Estágios de Aplicação a partir do Big Data

\begin{tabular}{|c|c|c|c|c|c|}
\hline \multirow{2}{*}{$\begin{array}{l}\text { Estratégia } \\
\text { Competitiva }\end{array}$} & \multirow{2}{*}{$\begin{array}{l}\text { Estágios } \\
\text { de Aplicaçầo } \\
\text { Objetivos } \\
\text { de valor }\end{array}$} & \multicolumn{2}{|l|}{ DESCOBERTAS } & \multicolumn{2}{|c|}{ PRODUÇÃO } \\
\hline & & O que? & Quem? & O que? & Quem? \\
\hline DIFERENCIAÇÃO & $\begin{array}{l}\text { Inovação } \\
\text { Produto } \\
\text { Serviço }\end{array}$ & $\begin{array}{l}\text { - sistema de controle de } \\
\text { telemetria } \\
\text { telecomando do do } \\
\text { saneamento } \\
- \text { hidrômetros mais } \\
\text { modernos e eficazes } \\
\text { - sistema de } \\
\text { monitoramento } \\
\text { inteligente cruzando as } \\
\text { diversas fontes de } \\
\text { dados }\end{array}$ & 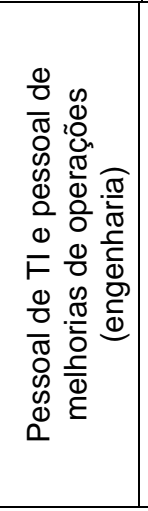 & $\begin{array}{l}\text { - dados on-line } \\
\text { sobre as estações } \\
\text { de abastecimento } \\
\text { tanto em relação a } \\
\text { informações } \\
\text { operacionais } \\
\text { quanto técnicas } \\
\text { - plano de troca de } \\
\text { hidrômetros a cada } \\
5 \text { anos } \\
\text { - aplicativo Big } \\
\begin{array}{l}\text { Data a a a ser } \\
\text { desenvolvido } \\
\text { implantado }\end{array} \\
\end{array}$ & 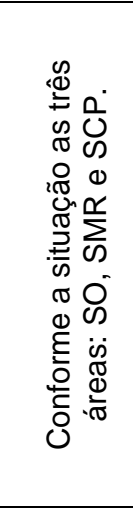 \\
\hline
\end{tabular}

Fonte: elaborado pelos autores.

Fase III - Solução a partir do Big Data, com a matriz 5V's definida na fase anterior, juntamente com a função objetivo e os requisitos/atributos, agora entram os aspectos de TI envolvendo o ferramental de busca das informações do Big Data, agrupando-as em clusters que fazem sentido e atendem a meta, a função objetivo e os requisitos/atributos. São quatro sub-fases - E.L.T.L. - Extract (diversas fontes), Load (DB systems - NoSql e HDFS), Trasform (reduce + filter), Load (transform results - unstructured and structured joinned). Uma estratégia de armazenagem contínua ou sob requisição do gestor deve ser feita de modo a registrar no banco de dados as fontes diversas de informações já identificadas na fase II.

Fase IV - Análises e Tendências, elaboração da matriz importância x desempenho (método GAP), ilustrada na Figura 3.

A partir da análise pela visão do CLIENTE pela importância na escala de 1 a 3 (ganhador de pedido), de 4 a 5 (qualificador de pedido), de 7 a 9 menos importante. Esses dados poderiam ser tratados dos atendimentos online, fone 0800 , redes sociais, matérias jornalísticas, ou enquetes online em sites específicos ou via empresas de pesquisa, para se obter informações externas sobre percepções da presença do Serviço Público junto à comunidade. 
Figura 3 - Matriz importância x desempenho (Método GAP) - Fonte: elaborado pelos autores.

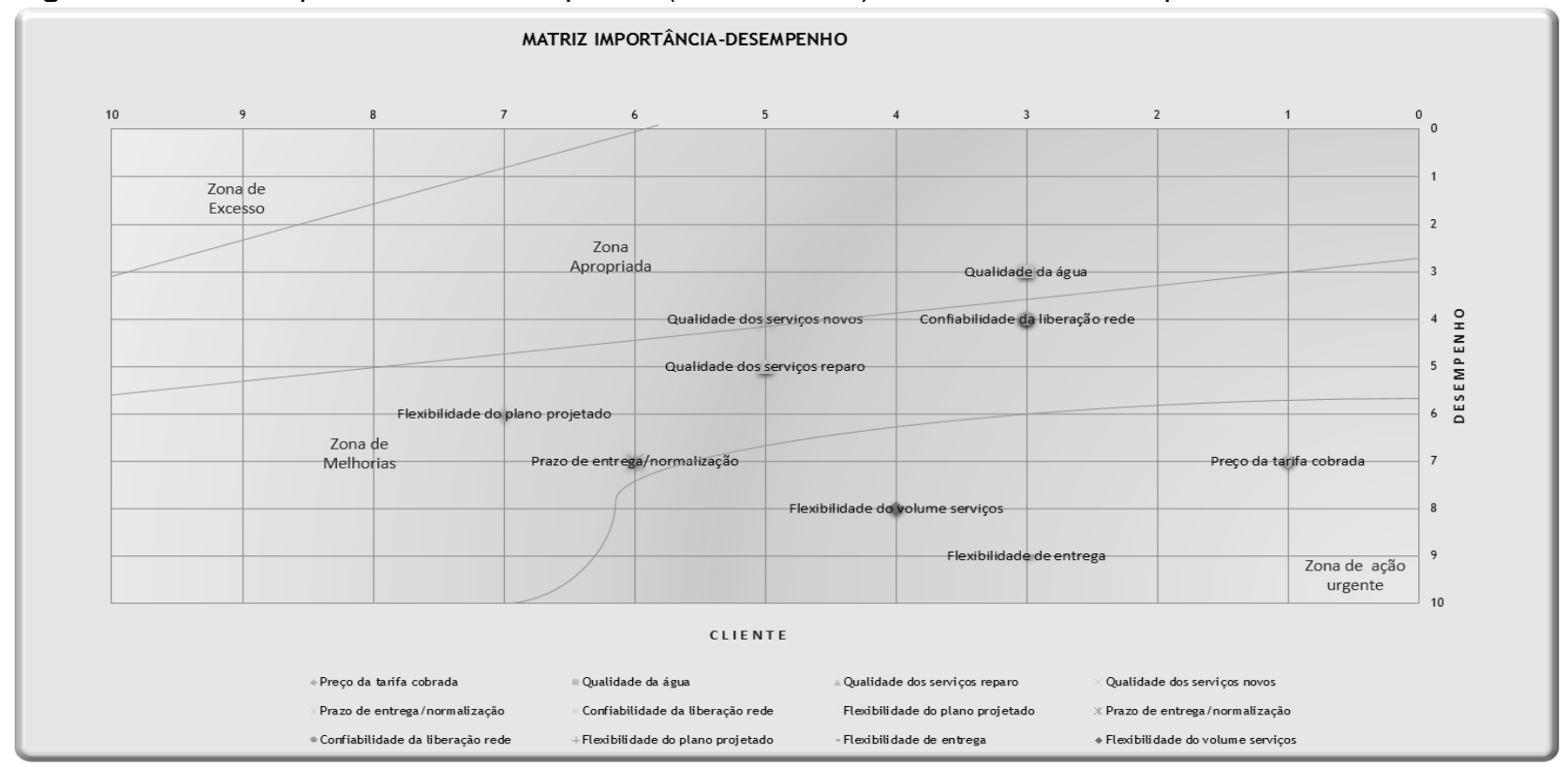

Fonte: elaborado pelos autores

A análise de DESEMPENHO tem a ver com os CONCORRENTES que, neste caso, podem ser outros serviços públicos semelhantes de outros municípios de mesmo porte com dados publicados que sejam iguais ou superiores, servindo de benchmarking, bem como empresas privadas que prestam esses serviços terceirizados em outros municípios e que publicam seus dados e matérias para fazer divulgação e marketing. Para essa análise de desempenho a importância na escala está baseada de 1 a 3 serviços são melhores que, de 4 a 6 mesmo que, de 7 a 9 , serviços são piores que.

Os objetivos de desempenho adotados para esta ilustração são: preço da tarifa cobrada, qualidade da água, qualidade dos serviços de reparo, qualidade dos serviços novos, prazo de entrega/normalização, confiabilidade da liberação da rede, flexibilidade do plano projetado, flexibilidade de entrega, flexibilidade do volume de serviços.

Pelo levantamento a Zona de Ação Urgente deve ser priorizada em relação a: i) preço da tarifa cobrada; ii) flexibilidade de entrega da rede funcionando; iii) flexibilidade do volume de serviços. Então, o decisor/gestor do Serviço Público a partir dessa Matriz Importância-Desempenho observando o que está presente na Zona de Ação Urgente, deveria tomar decisões para tentar reverter esse quadro, o 
que a partir das ações realizadas poderia ser novamente medido pelos dados do Big Data e novamente serem tabulados nessa Matriz.

Em um segundo momento, a Zona de Melhorias (ou a aprimorar) também deve ser considerada pelo decisor/gestor do Serviço Público, de modo a planejar ações para mitigar os objetivos que estão compondo momentaneamente esta região da Matriz. Igualmente, a partir das ações concretizadas novamente poderia haver uma medição pelos dados do Big Data e serem tabulados na Matriz.

Fase V - Decisões e Plano de Ação, após a identificação na Fase IV, de quais ações de melhoria serão prioritárias é necessário saber como estas ações serão gerenciadas na Rede de Valor e Operações (RVO), ou seja, quais decisões deverão ser tomadas em cada uma das atividades (Quadro 7).

Quadro 7 - Decisões e Plano de Ação - possível e a considerar.

\begin{tabular}{|c|c|c|}
\hline Aspecto Decisório & Decisões Possíveis & Pontos a considerar \\
\hline Suprimentos & $\begin{array}{l}\text { "número de fornecedores } x \text { item } \\
\text { comprado } \\
{ }^{*} \text { tipo de relacionamento com } \\
\text { fornecedor } \\
\text { "parcerias } \\
\text { "subcontratacão de atividades }\end{array}$ & $\begin{array}{l}\text { Listas de materiais (licitações), alocação } \\
\text { de máquinas e equipamentos, alocação } \\
\text { de pessoas (equipe). }\end{array}$ \\
\hline $\begin{array}{l}\text { Desenvolvimento } \\
\text { Produto / Serviço }\end{array}$ & $\begin{array}{l}\text { *tecnologias em gestão } \\
\text { *equipes e infraestrutura própria } \\
\text { *nível de utilização de TI } \\
\text { *nível de integração com parceiros }\end{array}$ & $\begin{array}{l}\text { Plano de ação detalhado para execução } \\
\text { do serviço, avaliando-se os impactos } \\
\text { locais na rede primária ou secundária de } \\
\text { água e esgoto. }\end{array}$ \\
\hline Execução/Produção & $\begin{array}{l}\text { "capacidade total de produção } \\
\text { *nível planejado x utilizado } \\
\text { *"estratégias nas sazonalidades } \\
\text { "aquisição de tecnologias e } \\
\text { equipamentos } \\
\text { ”nível de inovação em processos } \\
\text { "perfil exigido dos profissionais } \\
\text { *busca de melhorias contínuas }\end{array}$ & $\begin{array}{l}\text { Execução do plano de ação detalhado, } \\
\text { com prazo adequado e prazo com } \\
\text { contingências, conforme a situaçãa ao } \\
\text { se iniciarem os serviços. }\end{array}$ \\
\hline Distribuição & $\begin{array}{l}\text { *nível de customização dos } \\
\text { serviços e produtos } \\
\text { "sistemas próprios ou terceirizados } \\
\text { - rede e reservatórios } \\
\text { *nível de utilização da internet e de } \\
\text { TI }\end{array}$ & $\begin{array}{l}\text { Volta à normalidade de fornecimento da } \\
\text { rede de água aos contribuintes. }\end{array}$ \\
\hline Serviços agregados & $\begin{array}{l}\text { *tipo de serviço a ser agregado ao } \\
\text { produto ou ao serviço oferecido } \\
\text { "forma de gerenciamento das } \\
\text { operações de serviços } \\
\text { *rapidez, nível de personalização e } \\
\text { localização do serviço oferecido }\end{array}$ & $\begin{array}{l}\text { Outros serviços que se fizerem } \\
\text { necessários conforme a complexidade } \\
\text { do que for definido no plano de ação } \\
\text { e/ou durante a execução. }\end{array}$ \\
\hline
\end{tabular}

Fonte: elaborado pelos autores 
Se pelos resultados verificou-se que a Estratégia adotada chegou a níveis esperados então continuar a executar o Plano de Ação vigente, caso contrário, retornar à Fase I e, realizando o passo-a-passo de cada uma das Fases subsequentes, chegar a este ponto de novamente fazer uma avaliação.

\subsection{Algumas Projeções Comparativas}

O Presidente do Serviço Público declarou, em entrevistas, algumas metas a serem atingidas entre os anos de 2017 e 2018, listadas no Quadro 8:

Quadro 8 - metas traçadas para os anos 2017 e 2018 e comparadas com projeções do framework.

\begin{tabular}{|c|c|c|}
\hline Problema ou situação & Estratégia atual & Estratégia usando framework \\
\hline Vazamentos & $\begin{array}{l}\text { Média de } 10 \text { a } 15 \text { novos } \\
\text { vazamentos por dia, entre } 300 \text { e } \\
450 \text { vazamentos por mês em toda } \\
\text { a cidade, com atendimento a cerca } \\
\text { de } 20 \text { vazamentos/dia. }\end{array}$ & $\begin{array}{l}\text { Pela rapidez de detecção } \\
\text { estima-se que será possível } \\
\text { reduzir em } 50 \% \text { os vazamentos } \\
\text { pela remoção gradativa de } \\
\text { trechos de } 100 \mathrm{~m} \text { da tubulação } \\
\text { antiga. }\end{array}$ \\
\hline $\begin{array}{l}\text { Idade e tamanho da } \\
\text { tubulação da rede primária } \\
\text { e secundária }\end{array}$ & $\begin{array}{l}\text { Cerca de } 30 \text { anos, } \\
\text { aproximadamente } 50 \quad \mathrm{~km} \text {, } \\
\text { projetados em } 2018 \text { com recursos } \\
\text { próprios a substituição de } 3 \text { a } 4 \\
\text { km, levando em torno de } 17 \text { anos } \\
\text { para renovação total. }\end{array}$ & $\begin{array}{l}\text { Substituição programada de } \\
\text { cerca de } 400 \mathrm{~m} / \mathrm{mês} \text { projetando- } \\
\text { se um montante de } 4.400 \mathrm{~m} / \text { ano, } \\
\text { por volta de } 13 \text { anos para } \\
\text { renovação total. }\end{array}$ \\
\hline Reservatórios & $\begin{array}{l}\text { Existem } 29 \text { grandes reservatórios } \\
\text { já em funcionamento e projeta-se a } \\
\text { instalação de mais } 6 \text { reservatórios } \\
\text { menores para atender a pontos } \\
\text { críticos de abastecimento de água. }\end{array}$ & $\begin{array}{l}\text { A projetar com os dados de falta } \\
\text { de abastecimento e sua } \\
\text { recorrência localizada. }\end{array}$ \\
\hline Tratamento de esgoto & $\begin{array}{l}\text { Atualmente, chega a } 98 \% \text { de } \\
\text { tratamento de todo esgoto da } \\
\text { cidade, a meta é encerrar } 2018 \\
\text { com } 100 \% \text { tratado. }\end{array}$ & $\begin{array}{l}\text { A projetar com os dados de } \\
\text { futuras expansões do do } \\
\text { zoneamento urbano e industrial } \\
\text { da cidade. }\end{array}$ \\
\hline
\end{tabular}

Fonte: elaborado pelos autores com dados de entrevistas do Presidente.

\section{CONSIDERAÇÕES FINAIS}

Este artigo foi elaborado em 3 etapas. Na Etapa 1 foram realizados 5 passos de pesquisa e análise bibliográfica, sobre estratégia de produção e Big Data, com o intuito de se chegar, na Etapa 2, em 5 passos para a elaboração de um framework teórico-conceitual (BD-ProdStrateg). Na Etapa 3, realizou-se uma aplicação ilustrativa em uma unidade de serviço público municipal tentando-se alinhar a estratégia de produção de serviços com as fontes disponíveis de dados. 
O framework necessita de aplicação de campo mais detalhada e de possíveis novos ajustes. No entanto, buscou-se a simplificação de sua estrutura para favorecer a compreensão além de não prescrever nenhum tipo de ferramental tecnológico prévio ficando isso a cargo da situação de análise prevista e da expertise da equipe envolvida.

$\mathrm{Na}$ ilustração de aplicação, houve uma pequena projeção de serviços a serem realizados a partir de algumas análises genéricas de dados registrados: no site dessa unidade municipal, a partir das entrevistas concedidas a jornais e, em publicações em redes sociais (facebook).

De modo geral, a contribuição principal foi a sistematização da proposta do framework BD-ProdStrateg, utilizando-se um referencial teórico bem consolidado de autores de estratégia de produção e um referencial mais recente acerca de Big Data e de possibilidades a serem exploradas.

A ilustração de aplicação no Serviço Público gerou uma expectativa de continuidade e de busca por meios tecnológicos para se verificar em quanto tempo os principais problemas seriam solucionados e qual o grau de economia advinda dessas análises preditivas e interativas.

\section{REFERÊNCIAS}

AGRAWAL, D.; BERNSTEIN, P.; BERTINO, E.; DAVIDSON, S.; DAYAL, U.. Challenges and Opportunities with Big Data 2011-1. Purdue University. Purdue e-Pubs. Cyber Center Technical Reports. 2011. Disponível em: http://docs.lib.purdue.edu/cctech/1 Acesso em: abr. 2016.

AKTER, S.; WAMBA, S.F. Big Data analytics in e-commerce: a systematic review and agenda for future research. Eletronic Markets, 26, p. 173-194. 2016.

https://doi.org/10.1007/s12525-016-0219-0

AKTER, S.; WAMBA, S.F.; GUNASEKARAN, A.; DUBEY, R.; CHILDE, S.J.. How to improve firm performance using Big Data analytics capability and business strategy alignment?

International Journal of Production Economics, 182, p. 113-131. 2016.

https://doi.org/10.1016/.i.ipe.2016.08.018

BROWN, B.; CHUI, M.; MANYIKA, J. Are you ready for the era of 'big data'?. McKinsey

Quarterly, v. 4, n. 1, p. 24-35. 2011. https://doi.org/10.1016/..future.2014.08.007 
LIU, C.; YANG, C.; ZHANG, X.; CHEN, JINJUN External integrity verification for outsourced big data in cloud and IoT: A big Picture. Future Generation Computer Systems, v. 49, p. 58-67. 2015.

CHASE, R.B.; JACOBS, F.R.; AQUILANO, N.. Operations management for competitive advantage. $10^{\text {th }}$ ed., McGraw Hill. 2003.

CHEN,M.; MAO, S.; LIU, Y.. Big Data: a survey. Mobile network application. n. 19, p. 171209. 2014. https://doi.org/10.1007/s11036-013-0489-0

CAMPOS, F. R. A gestão da inovação em serviços intensivos em conhecimento: oportunidades e desafios do Big Data. 2015. 124 p. Dissertação (Mestrado em Política Científica e Tecnológica) - Instituto de Geociências, Universidade Estadual de Campinas, Campinas. 2015.

DAVENPORT, T.H.. Big Data at work: dispelling the myths, uncovering the opportunities. EUA: Harvard Business School Press. 2014.

DAVENPORT, T. H.; BARTH, P.; BEAN, R. How big data is different. MIT Sloan Management Review, v. 54, n. 1, p. 43. 2012.

DE MAURO, A.; GRECO, M.; GRIMALDI,M.. A formal definition of Big Data based on its essential features. Library Review, v. 65, n. 3, p. 122 - 135, 2016.

https://doi.org/10.1108/LR-06-2015-0061

DUBEY, R.; GUNASEKARAN, A.; CHILDE, S.J.; WAMBA, S.F.; PAPADOPOULOS, T.. The impact of Big Data on world-class sustainable manufacturing. The International Journal of Advanced Manufacturing Technology, v. 84, p. 631-645, 2016. https://doi.org/10.1007/s00170-015-7674-1

HALPER, F.; KRISHNAN, K.. TDWI Big Data Maturity Model Guide: Interpreting Your Assessment Score. TDWI Benchmark Guide 2013-2014, 2013.

HAYES, R.H.; PISANO, G.; UPTON, D.; WHELLWRIGHT, S.C.. Operation, strategy and technology: pursuing the competitive edge. Wiley. 2004.

HAYES, R.H.; WHELLWRIGHT, S.C.. Restoring our competitive edge: competing through manufacturing. New York: Free. 1984.

HILL, T.. Manufacturing Strategy: text and cases. London: MacMillan Business. 1995.

HöRTE, S.A.; LINDBERG, P.; TUNÄLV, C.. Manufacturing strategies in Sweden. International Journal of Production Research, v. 25, n. 11, p. 1573-1586, 1987.

IBM (2016). What is Big Data? Bringing Big Data to enterprise. Disponível em: www.ibm.com/software/data/bigdata. Acesso em: mar. 2016.

IDC IVIEW. Gantz J; Reinsel D. Extracting value from chaos. IDC iView, p 1-12, jun. 2011.

ISACA (2016). Big Data: Impactos e Benefícios. Disponível em:

http://www.isaca.org/Knowledge-Center/Research/ResearchDeliverables/Pages/Big-Data-

Impacts-and-Benefits.aspx. Acesso em: mar. 2016. 
JELINEK, M.; BERGEY, P.. Innovation as the strategic driver of sustainability: big data knowledge for profit and survival. IEEE Engineering Management Review, v. 41, n. 2, p. 14-22, 2013. https://doi.org/10.1109/EMR.2013.2259978

JOHNSON,G; SCHOLES, K.; WHITTINGTON, R.. Fundamentals of strategy. $1^{\text {st }}$ ed.. Prentice Hall. 2009.

KAMBATLA, K.; KOLLIAS, G.; KUMAR, V.; GRAMA, A.. Trends in Big Data analytics. Journal Parallel Distrib. Comput., n. 74, p. 2561-2573, 2014. https://doi.org/10.1016/j.jpdc.2014.01.003

LIU, C-H.. A Conceptual Framework of Analytical CRM in Big Data Age. International Journal of Advanced Computer Science \& Applications, v. 1, n. 6, p. 149-152. 2015. https://doi.org/10.14569/IJACSA.2015.060620

MEYER,A. de; NAKANE, J.; FERDOWS, K.. Flexibility: the next competitive battle: the manufacturing survey. Strategic Management Journal, v. 10, n. 2, p. 135-144, 1989. https://doi.org/10.1002/smj.4250100204

MAYER-SCHÖNBERGER, V.; CUKIER, K.. Big data: a revolution that will transform how we live, work, and think. Reino Unido: Houghton Mifflin Harcourt. 2013.

MAYER-SCHÖNBERGER, V.; CUKIER, K.. Big Data: como extrair volume, variedade, velocidade e valor da avalanche de informação cotidiana. 1. ed. Rio de Janeiro: Elsevier. 2013.

MCAFEE, A.; BRYNJOLFSSON, E.. Big Data: The Management Revolution. Harvard Business Review, October, 1-11. 2012.

MILLS, J.; PLATTS, K.; GREGORY, M.. A framework for the design of manufacturing strategy processes: a contingency approach. International Journal of Operations and Production Management, v. 15, n. 4, p. 17-49, 1995.

https://doi.org/10.1108/01443579510083596

NOVO, R. F.. Melhoria nas dimensões competitivas das empresas por meio do uso do Big Data. Dissertação (Mestrado Profissional em Gestão e Tecnologia em Sistemas Produtivos) - Centro Estadual de Educação Tecnológica Paula Souza, São Paulo, 2014.

OLOFSON, C.W.; VILLARS, R.L.; EASTWOOD, M.. Big data: What it is and why you should care. Paper, 2016.

IDC. Analyze the Future, 2011. Disponível em: www.idc.com. Acesso em: mar. 2016.

PAIVA, E.L.; CARVALHO JR., J.M.; FENSTERSEIFER,J.E.. Estratégia de produção e de operações: conceitos, melhores práticas, visão de futuro. 2. ed. Porto Alegre: Bookman. 2009.

PORTER, M.E.. Competitive strategy: techniques for analyzing industries and competitors. New York: Free Press. 1980.

SHENG, J.; AMANKWAH-AMOAH, J.; WANG, X.. A multidisplinary perspective of big data in management research. International Journal of Production Economics, n. 191, p. 97112, 2017. https://doi.org/10.1016/i.jpe.2017.06.006 
SIDDIQA, A.; HASHEM, I.A.T.; YAQOOB, I.; MARJANI, M.; SHAMSHIRBAND, S.; GANI, A.; NASARUDDIN, F.. A survey of Big Data management: taxonomy and state-the-art. Journal of Network and Computer Applications, n. 71, p. 151-166, 2016. https://doi.org/10.1016/j.jnca.2016.04.008

SIVARAJAH, U.; KAMAL, M.M.; IRANI, Z.; WEERAKKODY, V.. Critical analysis of Big Data challenges and analytical methods. Journal of Business Research, n. 70, p. 263-286, 2017. https://doi.org/10.1016/j.jbusres.2016.08.001

SLACK N.; CHAMBERS, S.; HARLAND, C.; HARRISON, A.; JOHNSTON, H.. Operations management. Pitman Publishing London. 1995.

SLACK N.; BRANDON-JONES, A.; JOHNSTON, R.; BETTS, A.. Operations and processes management: principles and practice for strategic impact. $4^{\text {th }}$ ed. Pearson. 2015.

SLACK N.; LEWIS,M.. Operations strategy. $2^{\text {nd }}$ ed.. Pearson Education Lt.. 2002.

SEO, W.; KIM, N. CHOI, S.. Big Data Framework for Analyzing Patents to Support Strategic R\&D Planning. In: DEPENDABLE, AUTONOMIC AND SECURE COMPUTING, 14TH INTL CONFERENCE ON PERVASIVE INTELLIGENCE AND COMPUTING, 2ND INTL CONF ON BIG DATA INTELLIGENCE AND COMPUTING AND CYBER SCIENCE AND TECHNOLOGY CONGRESS (DASC/PiCom/DataCom/CyberSciTech). [Proceedings...] 14th Intl C. IEEE, p. 746-753, 2016. https://doi.org/10.1109/DASC-PICom-DataComCyberSciTec.2016.131

WAMBA, S.F.; AKTER, S.; EDWARDS, A.; CHOPIN, G.; GNANZOU, D.. How 'big data' can make big impact: findings from a systematic review and a longitudinal case study.

International Journal of Production Economics, n. 165, p. 234-246, 2015. https://doi.org/10.1016/.i.jpe.2014.12.031

WAMBA, S.F.; GUNASEKARAN, A.; AKTER, S.; REN, S.J.; DUBEY, R.; CHILDE, S.J.. Big Data analytics and firm performance: effects of dynamic capabilities. Journal of Business Research, n. 70, p. 356-365, 2017. https://doi.org/10.1016/i.jbusres.2016.08.009

WANG, G., GUNASEKARAN, A.; NGAI, E.W.T.; PAPADOPOULOS, T. Big Data analytics in logistics and supply chain management: certain investigations for research and applications. International Journal of Production Economics, n. 176, p. 98-110, 2016. https://doi.org/10.1016/j.ijpe.2016.03.014

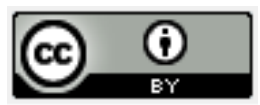

Artigo recebido em: 11/05/2018 e aceito para publicação em: 04/03/2020 DOI: http://dx.doi.org/10.14488/1676-1901.v20i1.3251 